$-u_{1} u_{2}^{\prime}>0$ implies that the derivative $d\left(u_{2} / u_{1}\right) / d x$ is less than or equal to zero, so that the equation $u_{1}=0$ can have no root $x_{1}^{\prime}>x_{2}$ preceding the first root $x_{2}^{\prime}$ of $u_{2}=0$. The points 1 and $1^{\prime}$ are therefore surely not separated by 2 and $2^{\prime}$ on the $\operatorname{arc} E$. This is the complete Jacobi condition as described in the reference of the footnote on the preceding page.

University of Chicago

\title{
A CONNECTED AND REGULAR POINT SET WHICH CONTAINS NO ARC*
}

BY R. L. MOORE

A point set is said to be connected im kleinen, $\uparrow$ or regular, at the point $P$ if, for every positive number $e$, there exists a positive number $d_{e}$ such that if $X$ is any point of $M$ at a distance from $P$ less than $d_{e}$ then $X$ and $P$ lie together in some connected $\ddagger$ subset of $M$ of diameter less than $e$. A point set which is regular (connected im kleinen) at every one of its points is said to be regular (connected im kleinen). The set $M$ is uniformly connected im kleinen if for each positive number $e$ there exists a positive number $d_{e}$ such that every two points of $M$ at a distance apart less than $d_{e}$ lie in a connected subset of $M$ of diameter less than $e$. If a point set $M$ is con-

* Presented to the Society, September 6, 1923.

$\dagger$ Cf. Hans Hahn, Ueber die allgemeinste ebene Punktmenge, die stetiges Bild einer Strecke ist, JAHresbericht DER Vereinigung, vol. 23 (1914), pp. 318-322. Also S. Mazurkiewicz, Sur les lignes de Jordan, Fundamenta Mathematicae, vol. 1 (1920), pp. 166-209. This conception, as applied to a simple closed curve, was used by Pia Nalli in the paper Sopra una definizioni di dominio piano limitato da una curva continua, senza punti multipli, Rendiconti di Palermo, vol. 32 (1911), pp. 391-401.

$\ddagger$ According to Hahn's formulation, $X$ and $P$ lie in a closed and connected subset of $M$ of diameter less than $e$. It has been customary with me to omit the stipulation that this subset should be closed. However, the set $M$ described below is connected im kleinen according to either definition. 
nected, connected im kleinen and closed, then every two of its points can* be joined by a simple continuous arc which lies wholly in $M$. In the present note I will show that there exists a connected and connected im kleinen point set which is not closed and which contains no arc whatsoever.

Let $S$ denote a unit square. For each positive integer $n$, divide $S$ into $n^{2}$ equal squares and let $S_{n}$ denote this set of $n^{2}$ squares. For each square $q$ of the set $S_{n}$ construct just one closed and connected point set $\dagger K_{q}$ which contains no arc and which lies wholly within $q$ except that it contains just four points on $q$, these four points being the mid-points of the four sides of $q$. For each $n$ let $M_{n}$ denote the set of points obtained by adding together the point sets $K_{q}$ for all squares $q$ of the set $S_{n}$. Let $M$ denote the point set

$$
M_{1}+M_{2}+M_{3}+\cdots \text {. }
$$

This point set is connected and uniformly connected im kleinen. But it contains no arc since it is the sum of a countable number of closed point sets no one of which contains an arc.

The University of TeXas

* R. L. Moore, A theorem concerning continuous curves, this Bulletin, vol. 23 (1917), pp. 233-236; S. Mazurkiewicz, loc. cit.; H. Tietze, Ueber stetige Kurven, Jordansche Kurvenbogen und geschlossene Jordansche Kurven, Mathematische Zeitschrift, vol. 5 (1919), pp. 284-291.

$\dagger$ That such a set exists may be easily seen with the help of an example described by B. Knaster in his paper Un continu dont tout sous-continu est indécomposable, Fundamenta Mathematicae, vol. 3 (1922), pp. 247-286. 